\title{
Transpiração e crescimento foliar de crisântemo em função da fração de água transpirável no substrato
}

\author{
Cláudio Renato Schlessner Kelling(1), Klaus Reichardt(2), Nereu Augusto Streck ${ }^{(3)}$, Isabel Lago ${ }^{(3)}$, \\ Alencar Junior Zanon ${ }^{(3)}$ e Marcelo Antônio Rodrigues ${ }^{(1)}$
}

\begin{abstract}
(1)Universidade Federal de Santa Maria, Colégio Politécnico, CEP97105-900 Santa Maria, RS, Brasil. E-mail: claudiokelling@politecnico.ufsm.br, marceloarodrigues2002@yahoo.com.br (2)Universidade de São Paulo, Centro de Energia Nuclear na Agricultura, Caixa Postal 96, CEP 13400-970 Piracicaba, SP, Brasil. E-mail: klaus@cena.usp.br ${ }^{(3)}$ Universidade Federal de Santa Maria, Centro de Ciências Rurais, Departamento de Fitotecnia, CEP 97105-900 Santa Maria, RS, Brasil. E-mail: nstreck2@yahoo.com.br, isalago08@yahoo.com.br, alencarzanon@yahoo.com.br
\end{abstract}

Resumo - O objetivo deste trabalho foi avaliar a resposta da transpiração e do crescimento foliar de cultivares de crisântemo (Dendranthema grandiflorum) ao conteúdo de água disponível no substrato, representado pela fração de água transpirável no substrato (FATSb). Os experimentos foram realizados em dois períodos, em delineamento inteiramente casualizado, com quatro cultivares de crisântemo (Cherie White, Bronze Repin, Yoapple Valley e Calabria), em duas condições hídricas (com ou sem deficiência hídrica), com 10 repetições. As plantas foram cultivadas em casa de vegetação, em vasos de $2,8 \mathrm{~L}$ preenchidos com substrato. A FATSb, a transpiração e o crescimento foliar foram determinados diariamente durante o período de deficiência hídrica. As FATSb críticas médias, indicativas de que a transpiração e o crescimento foliar começam a ser afetados, foram respectivamente de 0,63 e 0,68 para 'Cherie White', 0,60 e 0,69 para 'Bronze Repin', 0,53 e 0,59 para 'Yoapple Valley', e 0,51 e 0,54 para 'Calabria'. A diminuição da água disponível no substrato provoca a redução do crescimento foliar antes de restringir a transpiração. As cultivares Cherie White e Bronze Repin são mais tolerantes ao deficit hídrico por fechar os estômatos antes e conservar mais a água no substrato do que as cultivares Yoapple Valley e Calabria.

Termos para indexação: Dendranthema grandiflorum, área foliar, deficiência hídrica, fechamento estomático, manejo da irrigação.

\section{Transpiration and leaf growth of chrysanthemum as a function of the fraction of transpirable water in the substrate}

\begin{abstract}
The objective of this work was to evaluate the response of transpiration and leaf growth of chrysanthemum (Dendranthema grandiflorum) cultivars to available water in the substrate, represented by the fraction of transpirable substrate water (FTbSW). The experiments were performed in two periods, in a completely randomized design, with four chrysanthemum cultivars (Cherie White, Bronze Repin, Yoapple Valley, and Calabria), under two substrate water conditions (with or without water stress), with 10 replicates. Plants were grown in a greenhouse, in 2.8 -L pots with substrate. FTSbW, transpiration, and leaf growth were measured daily, during the period of water deficit. The average threshold FTSbW, indicating that transpiration and leaf growth began to be affected, was respectively 0.63 and 0.68 for 'Cherie White', 0.60 and 0.69 for 'Bronze Repin', 0.53 and 0.59 for 'Yoapple Valley', and 0.51 and 0.54 for 'Calabria'. Available water decrease in the substrate reduces leaf growth before restricting transpiration. The Cherie White and Bronze Repin cultivars are more tolerant to water deficit by closing the stomata earlier and retaining more water in the substrate than the Yoapple Valley and Calabria cultivars.
\end{abstract}

Index terms: Dendranthema grandiflorum, leaf area, water stress, stomatal closure, irrigation management.

\section{Introdução}

A redução da disponibilidade de água no solo afeta o metabolismo, o transporte, a translocação de solutos na planta, a turgescência celular, a expansão celular, e a abertura e o fechamento dos estômatos (Taiz \& Zeiger, 2009). Em condição de deficit hídrico no solo, a redução do crescimento e as perdas de rendimento das culturas ocorrem, principalmente, em razão do fechamento estomático que diminui a entrada de $\mathrm{CO}_{2}$, com consequente redução da fotossíntese (Streck, 2004).

As plantas respondem ao deficit hídrico conforme a intensidade do estresse de água no solo, o genótipo, o 
estágio de desenvolvimento e o tipo de órgão e célula considerados, e podem apresentar respostas em nível morfológico, fisiológico, celular e metabólico (Bray, 1997). Nessa condição, as plantas apresentam algumas estratégias de defesa - como a inibição da expansão foliar, a expansão do sistema radicular, o fechamento estomático, a aceleração da senescência e a abscisão das folhas -, que podem exercer importante função na sobrevivência da espécie (Moreno F., 2009).

O conceito da fração de água transpirável no solo (FATS) é considerado como o melhor indicador da quantidade real de água no solo que pode ser extraída pelas plantas para a transpiração (Santos \& Carlesso, 1998). No conceito da FATS, o conteúdo de água no solo, consumido pela planta na transpiração, está em um intervalo entre o valor do conteúdo de água no solo à capacidade de campo, quando a transpiração é potencial, e o conteúdo de água no solo, quando a transpiração da planta é igual a $10 \%$ da potencial (Sinclair \& Ludlow, 1986). A fração de água transpirável no solo, quando se inicia a redução da transpiração e do crescimento foliar das plantas, é chamada de FATS crítica (Lago et al., 2011, 2012).

$\mathrm{Na}$ literatura, há trabalhos que relatam o uso da metodologia da FATS em várias espécies. A FATS crítica medida em ervilha, em casa de vegetação com controle do ambiente, foi de 0,55 para a transpiração e crescimento foliar (Lecoeur \& Sinclair,1996). Em videira, a FATS crítica foi de 0,35, tanto para transpiração como para crescimento foliar (Bindi et al., 2005). Em mudas de eucalipto, em casa de vegetação sem controle ambiental, a FATS crítica foi de 0,90 (Eucalyptus grandis) e 0,70 (Eucalyptus saligna) (Martins et al., 2008). Em arroz cultivado em campo, Davatgar et al. (2009) encontraram FATS de 0,46 e 0,44 para a transpiração e crescimento foliar, respectivamente. Em outro estudo com arroz de terras altas, cultivado em casa de vegetação, a FATS crítica variou de 0,28 a 0,42, na fase vegetativa, e de 0,39 a 0,50 na fase reprodutiva (Heinemann et al., 2011).

Além da variação da FATS entre espécies, outros estudos apresentaram variação entre tipos de solo e substratos, entre genótipos dentro da mesma espécie, e também entre épocas de cultivo. Wahbi \& Sinclair (2007) observaram que os valores de FATS crítica da transpiração de milho e soja diferem quanto ao solo utilizado - mineral e "artificial" (substrato comercial), com valores entre 0,28 e 0,34 , no solo mineral, e 0,60 a 0,80 , no substrato comercial.

Lago et al. $(2011,2012)$ verificaram, na cultura da batata e da mandioca, que o valor de FATS crítica que começa a afetar a transpiração e o crescimento foliar difere entre as espécies, entre as cultivares dentro de cada espécie e em condições de dias com baixa e com alta demanda evaporativa do ar. Ray et al. (2002) e Lago et al. (2011) consideram que em condição de alto deficit de pressão de vapor do ar (DPV), as plantas podem apresentar alta taxa de transpiração, o que exigiria maior fluxo de água do solo para suprir a transpiração, poderia levar à limitação do fluxo transpiratório, com um conteúdo de água maior no solo, e resultaria em maiores valores de FATS crítica

Segundo Souza et al. (2014), a FATS é um método eficiente para separar diferentes clones de batata quanto às respostas ao deficit hídrico. Um valor de FATS crítica maior indica que a planta fecha os seus estômatos mais no início do deficit hídrico e, assim, conserva água no solo por mais tempo, o que lhe confere maior tolerância ao deficit hídrico no solo.

O crisântemo, Dendranthema grandiflorum, se caracteriza como planta herbácea perene, mas é cultivada comercialmente como planta anual. Seja como flor de corte ou de vaso, é uma das espécies de plantas ornamentais mais comercializadas no Brasil. Em 2011, a comercialização de crisântemos no Veiling Holambra ultrapassou 9,3 milhões de vasos (Rodrigues (2013).

Há poucas informações relacionadas à cultura do crisântemo, por ser recente no país, em comparação a outras culturas (Rego et al., 2009). No momento, estão disponíveis, para as condições brasileiras, técnicas básicas de cultivo de crisântemo (espaçamento, controle fotoperiódico, adubação, combate a pragas e doenças). Sobre a resposta ao deficit hídrico no solo, as poucas informações que existem estão relacionadas à resposta das plantas ao potencial de água no solo (Farias et al., 2012). Assim, são necessários mais estudos sobre a resposta da cultura à deficiência hídrica, principalmente, avaliados pela FATS, que é considerada como o melhor indicador da quantidade real de água disponível para a transpiração das plantas (Santos \& Carlesso, 1998).

O objetivo deste trabalho foi avaliar a resposta da transpiração e do crescimento foliar de cultivares de crisântemo ao conteúdo de água disponível no 
substrato, representado pela fração de água transpirável no substrato (FATSb).

\section{Material e Métodos}

Os experimentos foram realizados na área experimental do Setor de Floricultura do Colégio Politécnico, da Universidade Federal de Santa Maria, em Santa Maria, RS $\left(29^{\circ} 43^{\prime} \mathrm{S}, 53^{\circ} 43^{\prime} \mathrm{W}, 94 \mathrm{~m}\right.$ de altitude), em dois períodos - Época1, instalado em 26/11/2011, e Época2, em 15/6/2012 -, em casa de vegetação climatizada. Quatro cultivares de crisântemo, produzidas comercialmente, foram utilizadas: duas de vaso, Cherie White e Yoapple Valley, e duas de corte, Bronze Repin e Calabria.

Utilizou-se o delineamento utilizado inteiramente casualizado, em arranjo bifatorial, com dois tratamentos para cada cultivar, tendo-se como fator A as quatro cultivares de crisântemo, e como fator B os dois regimes hídricos (T1, sem deficiência hídrica, e T2, com deficiência hídrica), com 10 repetições em cada tratamento. Cada repetição constituiu-se de um vaso com uma planta, no total de 20 plantas por cultivar e 80 plantas por experimento. As 10 repetições do $\mathrm{T} 1$, em que as plantas cresceram sem aplicação da deficiência hídrica, foram usadas como testemunhas e, nas outras 10 repetições referentes ao $\mathrm{T} 2$, foi imposta a deficiência hídrica.

As mudas de crisântemo foram obtidas por estacas provenientes de uma empresa, tratadas com promotor de enraizamento ácido indolbutírico (AIB) e colocadas em bandejas de plástico preenchidas com cascas de arroz carbonizadas, as quais foram dispostas sob uma bancada com um sistema de irrigação por nebulização. Após o enraizamento, as estacas das cultivares de vaso e de corte foram transplantadas para vasos com o seguinte substrato de cultivo: dois volumes de solo mineral do horizonte B textural, de um solo classificado como Argisolo Vermelho distrófico típico; dois volumes de turfa; um volume de casca de arroz queimada, acrescido de $2 \mathrm{~g}$ de fertilizante solúvel PGMix $\left(14 \% \mathrm{~N}, 16 \% \mathrm{P}_{2} \mathrm{O}_{5}, 18 \% \mathrm{~K}_{2} \mathrm{O}, 7 \% \mathrm{~S}, 0,03 \%\right.$ $\mathrm{B}, 0,12 \% \mathrm{Cu}, 0,16 \% \mathrm{Mo}$ e $0,2 \% \mathrm{Mn}$ ); e $5 \mathrm{~g}$ de calcário dolomítico extrafino (PRNT 90\%), para cada litro de substrato preparado. $\mathrm{O}$ substrato utilizado apresenta as seguintes características físicas: $63,3 \%$ de porosidade total; $30,9 \%$ de microporos; $32,4 \%$ de macroporos; densidade $0,71 \mathrm{~g} \mathrm{~cm}^{-3} ; 190 \mathrm{~g} \mathrm{~kg}^{-1}$ de argila; e $95 \mathrm{~g} \mathrm{~kg}^{-1}$ de matéria orgânica.

Cada repetição constituída de uma planta foi cultivada em um vaso de plástico de 2,8 litros. As paredes externas dos vasos foram pintadas de branco, para reduzir a absorção de radiação solar, o que aumentaria a temperatura do substrato. Os vasos foram dispostos sobre uma bancada metálica com $0,90 \mathrm{~m}$ de altura. Quando necessário, realizou-se a suplementação de luminosidade, pela exposição das plantas a uma condição de dia longo (superior a 14 horas), para assim evitar a indução floral das plantas.

O desempenho das plantas submetidas ao deficit hídrico foi verificado pela metodologia da fração de água transpirável no substrato (FATSb) em dois estágios de deficiência hídrica, conforme Sinclair \& Ludlow (1986); no estágio I, a água está disponível livremente no solo, sem deficiência hídrica para as plantas, e a condutância estomática e transpiração são potenciais; no estágio II, a água disponível no solo diminui, e a condutância estomática e a transpiração decrescem, para manter o balanço hídrico e a turgescência celular.

A aplicação dos regimes hídricos T1 e T2 iniciouse em 9/12/2011, no primeiro experimento (Época1), quando as plantas apresentavam média de 20, 12, 17 e 13 folhas acumuladas na haste principal nas cultivares Cherie White, Bronze Repin, Yoapple Valley e Calabria, respectivamente, e em 7/7/2012, no segundo experimento (Época2), com média de 19, 12,15 e 18 folhas acumuladas na haste principal das cultivares Cherie White, Bronze Repin, Yoapple Valley e Calabria, respectivamente.

Por ocasião do início dos experimentos, os vasos foram saturados e submetidos à drenagem por 30 min, quando atingiram a capacidade de campo. Os vasos foram, então, cobertos com filme plástico, após a saturação, para minimizar a perda de água pela evaporação do solo, com a segurança de que a água retirada do solo tivesse ocorrido apenas pela transpiração das plantas.

Para descontar uma possível evaporação através do filme plástico que cobria a superfície do substrato, foram utilizados seis vasos-controle, preenchidos com substrato, sem plantas e cobertos com filme plástico. Em três dos vasos, foi reposta a quantidade de água evaporada e, nos outros três, não se fez a reposição da água evaporada. As médias referentes à evaporação dos vasos-controle foram descontadas da água transpirada 
no T1 e no T2. Em caso de ocorrência de alguma drenagem nos vasos, o valor correspondente à água drenada era também subtraído da transpiração diária ocorrida em cada repetição.

Em seguida, determinou-se a massa inicial de cada vaso e, então, aplicou-se a deficiência hídrica nos vasos referentes ao T2, que não foram mais irrigados até o final do experimento, ou seja, até a transpiração (TR) das plantas do T2 atingir $10 \%$ da transpiração das plantas do T1, o que ocorreu antes de as plantas atingirem o ponto de murcha permanente.

Os vasos foram pesados diariamente, às 17:00 h, em uma balança eletrônica com capacidade de $8,1 \mathrm{~kg}$ e precisão de $0,1 \mathrm{~g}$. Após a pesagem, cada vaso do $\mathrm{T} 1$ representou a resposta à quantidade de água que a planta transpirou desde o dia anterior. A perda diária de água pelas plantas do $\mathrm{T} 1$ foi determinada pela seguinte equação: $\mathrm{T} 1$ = massa de cada vaso no dia da pesagem - massa inicial do mesmo vaso no dia do início do experimento. Em seguida, calculou-se a média da perda diária de água, nas 10 plantas que constituíram o tratamento, em cada cultivar.

A análise dos dados foi realizada para cada vaso, tendo-se comparado a transpiração relativa (TR) com a fração de água transpirável no solo (FATSb). A TR foi determinada pela equação descrita por Sinclair \& Ludlow (1986): TR = perda diária de água pelas plantas do T2 / média da perda diária de água das plantas do T1, considerada a primeira normalização (TR1), realizada com o objetivo de os dados ficarem entre os valores de 0 a 1 . A perda diária de água pelas plantas do $\mathrm{T} 2$ foi obtida pela seguinte equação: T2 = massa de cada vaso no dia - massa do mesmo vaso no dia anterior.

Ao finalizar o experimento - quando as plantas do T2 atingiram transpiração relativa menor ou igual a $10 \%$ da transpiração das plantas do T1 -, determinouse a FATSb para cada vaso do T2, para cada dia, a partir do último para o primeiro dia de deficiência hídrica. A FATSb foi determinada pela seguinte equação: FATSb = (massa de cada vaso em cada dia massa final) / (massa inicial de cada vaso - massa final) (Sinclair \& Ludlow, 1986). A massa final de cada vaso foi considerada como a massa do vaso quando a TR alcançou $10 \%$ ou menos, em relação à transpiração das plantas do T1, admitindo-se que, abaixo dessa taxa de transpiração, os estômatos estão fechados, e a perda de água ocorre apenas pela transpiração epidérmica, o que se caracteriza como o estágio III da transpiração (Sinclair \& Ludlow, 1986).

A área foliar $\left(\mathrm{AF}, \mathrm{cm}^{2}\right)$ de cada planta foi determinada diariamente, após o início da aplicação dos tratamentos, e calculada pelo somatório da AF de todas as folhas individuais da planta. Para o ajuste da equação para a estimativa da área foliar, realizou-se um ensaio em branco com cinco vasos de cada cultivar. Coletaram-se 60 folhas de cada cultivar (20 pequenas, 20 médias e 20 grandes), em que foram medidos o comprimento (C) e a maior largura de cada folha que, em seguida, foram escaneadas. Com a aplicação do programa Quant (Versão 1.0.1.), determinou-se a área foliar individual. No ajuste da equação para quantificar a área foliar, utilizou-se o programa Table Curve. Os melhores ajustes mostraram que a medida do comprimento das folhas é suficiente na determinação da área foliar, tendo-se em vista os altos valores de coeficiente de determinação $\left(\mathrm{R}^{2}\right)(0,971,0,977,0,967$ e 0,935). As equações ajustadas para determinação da área foliar, em que $\mathrm{X}$ é o comprimento da folha, foram: 'Cherie White', $\mathrm{AF}=0,19 \mathrm{X}^{2,08}$; 'Bronze Repin', $\mathrm{AF}=0,18 \mathrm{X}^{2,14}$; 'Yoapple Valley', $\mathrm{AF}=0,33 \mathrm{X}^{1,96}$; 'Calabria', $\mathrm{AF}=0,26 \mathrm{X}^{2,01}$.

Com base nos dados de AF total diária, calculouse o crescimento foliar relativo (CFR) diário, para cada cultivar, pela seguinte equação: $\mathrm{CFR}=$ aumento de AF total de cada planta do T2 / aumento médio de AF total pelas plantas do T1, considerada a primeira normalização (CFR1), com o objetivo de os dados ficarem entre 0 e 1 . A diferença entre a AF total de cada planta no dia e a AF total da mesma planta no dia anterior possibilitou a determinação diária do aumento de AF total pelas plantas do T1 e do T2 (Lecoeur \& Sinclair, 1996).

A segunda normalização foi realizada com o intuito de reduzir as variações entre plantas, causadas pelas condições ambientais da casa de vegetação. Para realizar esta segunda normalização, procurou-se inicialmente, determinar uma FATSb acima da qual os valores de TR e CFR, obtidos na primeira normalização, apresentassem variabilidade maior nas plantas, cujo valor verificado nos experimentos foi de 0,60. Então, calculou-se a média dos valores de TR e CFR nas repetições com FATSb igual ou maior que 0,60 , e todas as determinações iniciais de TR e CFR foram divididas por estas médias. A segunda normalização é representada pelas equações, $\mathrm{TR} 2=\mathrm{TR} 1 / \overline{\mathrm{TR} 1}$ 
e $\mathrm{CFR} 2=\mathrm{CFR} 1 / \overline{\mathrm{CFR} 1}$, em que: $\overline{\mathrm{TR} 1}$ e $\overline{\mathrm{CFR} 1}$ representam a média dos dias com FATSb acima de 0,60 , respectivamente.

Ajustou-se uma equação logística para os dados referentes à TR e ao CFR, obtidos na segunda normalização (TR2 e CFR2), em função da FATSb (Sinclair \& Ludlow, 1986; Lecoeur \& Sinclair, 1996): $\mathrm{Y}=\{1 /[(1+\exp (-\mathrm{a}(\mathrm{X}-\mathrm{b})]\}$. Nesta equação, $\mathrm{Y}$ é a variável dependente TR ou CFR, X é a FATSb, e a e b são coeficientes empíricos, que foram determinados por meio de uma regressão não linear pelo programa SAS (SAS Institute, Cary, NC, EUA). A FATSb crítica (FATSbc) para a TR e para o CFR, foi determinada para uma TR ou CFR de 0,95 (Lago et al., 2011, 2012). A FATSbc foi determinada pela equação utilizada por Pinheiro (2013): FATSbc $=\mathrm{b}-\ln (0,0526) / \mathrm{a}$, em que a e b são coeficientes empíricos, que foram determinados por meio de regressão não linear no programa SAS (SAS Institute Inc., Cary, NC, EUA), para cada repetição.

As variáveis meteorológicas temperatura do bulbo seco e do úmido, às 15:00 h, e as temperaturas mínima e máxima diárias do ar foram medidas diariamente, no interior de um miniabrigo meteorológico de madeira, pintado de branco e posicionado no centro da bancada. Com base nos dados de temperatura do bulbo seco e do úmido, às 15:00 $\mathrm{h}$, determinou-se o deficit de pressão de vapor do ar (DPV). A densidade de fluxo de radiação solar global diária incidente foi estimada com base no brilho solar diário, obtido na estação meteorológica convencional do $8^{\circ}$. Distrito de Meteorologia, localizada a aproximadamente $0,5 \mathrm{~km}$ da casa de vegetação. Assumiu-se uma transmissividade da cobertura de plástico de 80\% (Buriol et al., 1995).

\section{Resultados e Discussão}

As médias das temperaturas máximas e mínimas do ar foram, respectivamente, no experimento Época 1 (aplicação do deficit hídrico em 9/12/2011), 32,2 e $19,1^{\circ} \mathrm{C}$ e, no experimento Época2 (aplicação do deficit hídrico em $7 / 7 / 2012$ ), $26,9^{\circ} \mathrm{C}$ e $14,7^{\circ} \mathrm{C}$ (Figura $1 \mathrm{~A}$ ). A densidade de fluxo de radiação solar global diária incidente, estimada no interior da casa de vegetação, foi maior no experimento Época1 do que no Época2, tendo-se verificado média de 17,01 e $7,90 \mathrm{MJ} \mathrm{m}^{-2}$ por dia, respectivamente (Figura $1 \mathrm{~B}$ ). O deficit de pressão de vapor (DPV) às 15:00 $\mathrm{h}$ apresentou valor médio
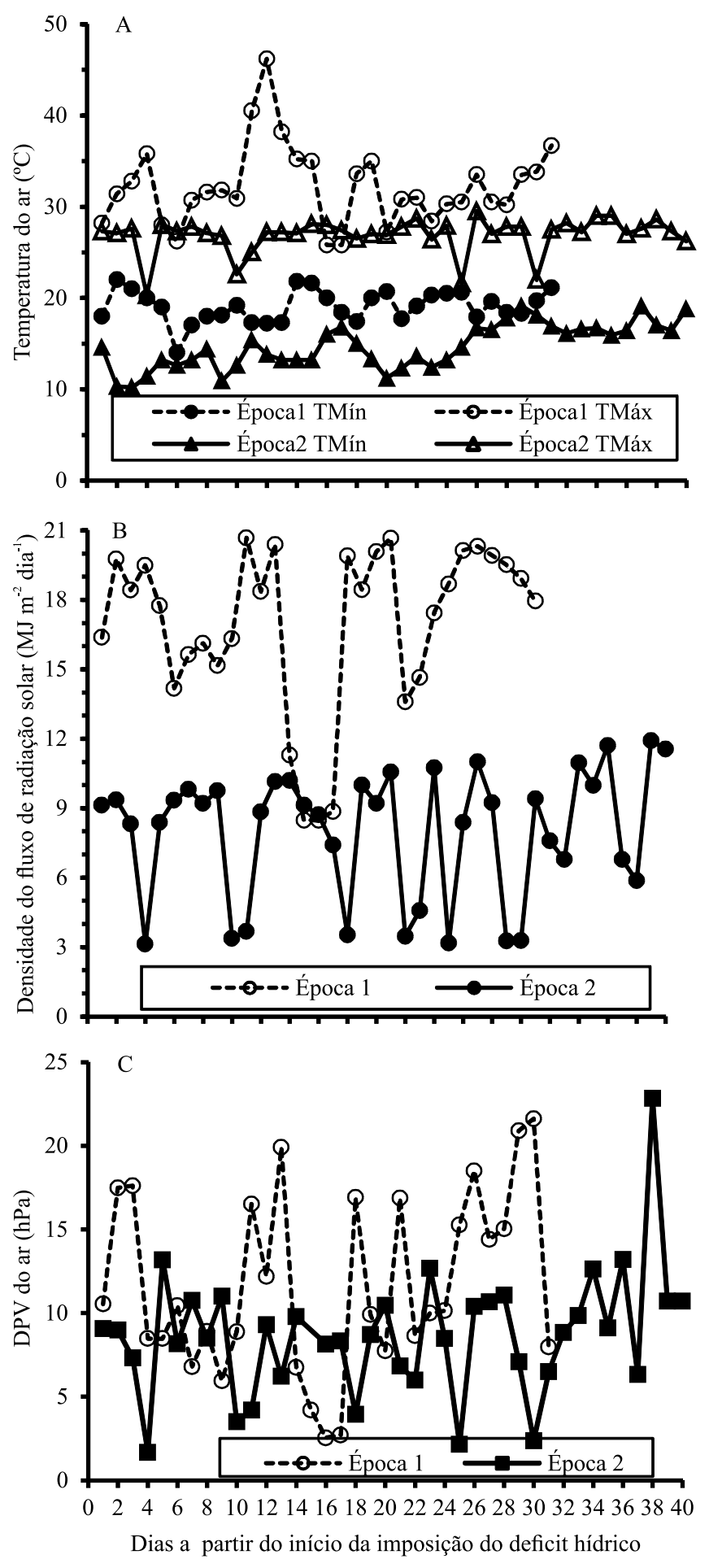

Figura 1. Temperaturas mínima (Tmín) e máxima (Tmáx) diárias do ar, expressas em graus centígrados (A); densidade de fluxo de radiação solar global diária incidente estimada, expressa em MJ m${ }^{-2}$ dia $^{-1}(B)$; e deficit de pressão de vapor do ar (DPV) diário, expresso em hectopascals (C), no interior da casa de vegetação, durante os experimentos com crisântemo (Época1 e Época2). 
de 11,68 hPa, no experimento Época1, superior ao observado no experimento Época2, que apresentou valor médio de 8,77 hPa (Figura $1 \mathrm{C}$ ).

Apesar de ter havido controle das condições ambientais (temperatura do ar) no interior da casa de vegetação, houve diferenças entre as épocas, o que resultou em menor duração do experimento Época1 (31, 20, 13 e 19 dias, respectivamente, para 'Cherie White', 'Bronze Repin', 'Yoapple Valley' e 'Calabria') do que no experimento Época2 (40, 33, 31 e 25 dias, respectivamente, para 'Cherie White', 'Bronze Repin', 'Yoapple Valley' e 'Calabria'). A menor duração do experimento Época1 é atribuída aos maiores valores de temperatura do ar, densidade de fluxo de radiação solar global diária incidente e de DPV (Figura 1) nessa época de cultivo, o que resultou em maior demanda evaporativa do ar. Porém, apesar de apresentar diferença de DPV entre os experimentos, nos dois casos os valores são menores do que $15 \mathrm{hPa}$ o que, segundo Kiniry et al. (1998), caracteriza uma condição de baixa demanda atmosférica.

A FATSbc para a transpiração é apresentada na Figura 2. Observa-se que o fechamento estomático começa a ocorrer com FATSbc média de 0,62 e 0,65 para a cultivar Cherie White, de 0,60 e 0,60 para Bronze Repin, de 0,56 e 0,51 para Yoapple Valley, e de 0,48 e 0,54 para Calabria, nos experimentos Época1 e Época2 respectivamente.

Os valores de FATSbc para transpiração, obtidos no presente estudo, se aproximam dos constatados por Wahbi \& Sinclair (2007) em milho e feijão, cultivados em substrato comercial, e aos encontrados por Lecoeur \& Sinclair (1996) na cultura da ervilha (FATSbc de 0,55) em casa de vegetação, com controle de temperatura $\left(20\right.$ a $\left.30^{\circ} \mathrm{C}\right)$. Porém, são superiores aos obtidos em: soja, 0,40, por Sinclair \& Ludlow (1986); videira, 0,35, por Bindi et al. (2005); arroz, 0,46, por Davatgar et al. (2009); e por Wahbi \& Sinclair (2007), para milho e feijão cultivados em solo mineral. Assim, se comparados a resultados de culturas agrícolas avaliadas em solo mineral, os valores de FATS crítica para o crisântemo cultivado em substrato são maiores do que para a maioria das culturas.

As cultivares Cherie White e Bronze Repin apresentaram FATSbc maior do que as da Yoapple Valley e Calabria. Isso mostra que as cultivares Cherie White e Bronze Repin apresentam um mecanismo de controle estomático mais eficiente, conservando água no substrato por mais tempo, o que pode ter prolongado o número de dias para suas plantas atingirem $10 \%$ da transpiração das plantas sem deficit, nas duas épocas experimentais. Neste contexto, também pode-se levar em consideração o fato de que algumas cultivares de crisântemo toleram maiores tensões de água no solo do que outras, conforme relatado por Farias et al. (2012).

Verifica-se que a FATSbc correspondente ao início da redução do crescimento foliar foi de 0,66 e 0,71 para 'Cherie White', 0,68 e 0,71 para 'Bronze Repin', 0,56 e 0,62 para 'Yoapple Valley', e 0,48 e 0,60, para 'Calabria', para Época1 e Época2, respectivamente (Figura 3). Os valores de FATSbc, verificados para o crescimento foliar, se assemelham aos encontrados por Lecoeur \& Sinclair (1996) para ervilha $(0,55)$, em casa de vegetação com controle ambiental, e são superiores aos observados por Bindi et al. (2005) em videira $(0,35)$ e por Davatgar et al. $(2009)$ em arroz $(0,44)$.

$\mathrm{O}$ crescimento foliar foi reduzido antes que houvesse redução da transpiração (Figuras 2 e 3). Este resultado confirma outros anteriores de que o crescimento foliar é mais sensível ao deficit hídrico do que a transpiração, e que ocorre redução do crescimento foliar antes de o mecanismo de fechamento estomático ser ativado (Martins et al., 2008; Lago et al., 2011, 2012). Isto ocorre em razão da redução do turgor, com a consequente diminuição da elasticidade da parede celular e aumento da concentração de solutos, que induzem à diminuição da divisão e expansão celular e, assim, à diminuição do crescimento foliar, confirmando ser esta a primeira linha de defesa contra o deficit hídrico (Taiz \& Zeiger, 2009).

Verificando-se os valores de FATSbc para TR (Figura 2) e para CFR (Figura 3), percebe-se uma resposta fisiológica de 'Cherie White' e 'Bronze Repin', no sentido de conservar a umidade no substrato, já que apresentaram FATSbc maior. Este resultado corrobora os de Souza et al. (2014), que concluíram que clones de batata, que apresentaram FATS crítica maiores, foram os mais tolerantes ao deficit hídrico no solo, pois fecham os seus estômatos antes, e isto conserva água no solo por mais tempo. 'Yoapple Valley' e 'Calabria', que apresentaram os menores valores de FATSbc para a transpiração e para o crescimento foliar, atingiram $10 \%$ da transpiração das plantas sem deficit (fim do experimento), em menos dias do que 'Cherie White' e 'Bronze Repin', ou seja, o ressecamento do substrato 

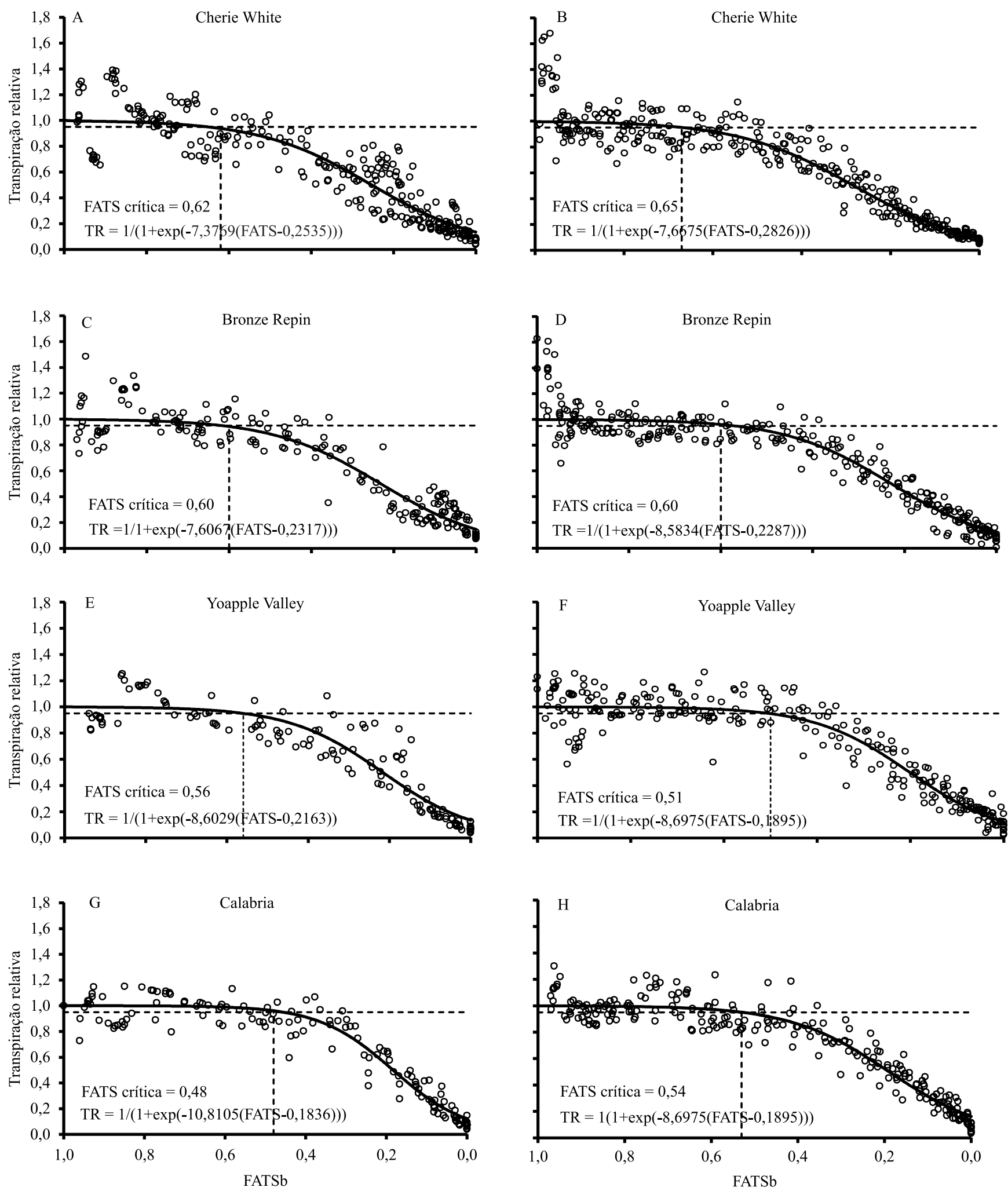

Figura 2. Transpiração relativa (TR), em função da fração de água transpirável no substrato (FATSb), para as cultivares de crisântemo Cherie White, Bronze Repin, Yoapple Valley e Calabria, cultivadas em casa de vegetação, em dois experimentos: com início da aplicação do deficit hídrico respectivamente em: 9/12/2011, Época1 (A, C, E e G); e 7/7/2012, Época2 (B, D, F e H). FATSb crítica, fração de água transpirável no substrato, quando se inicia a redução da transpiração das plantas. 

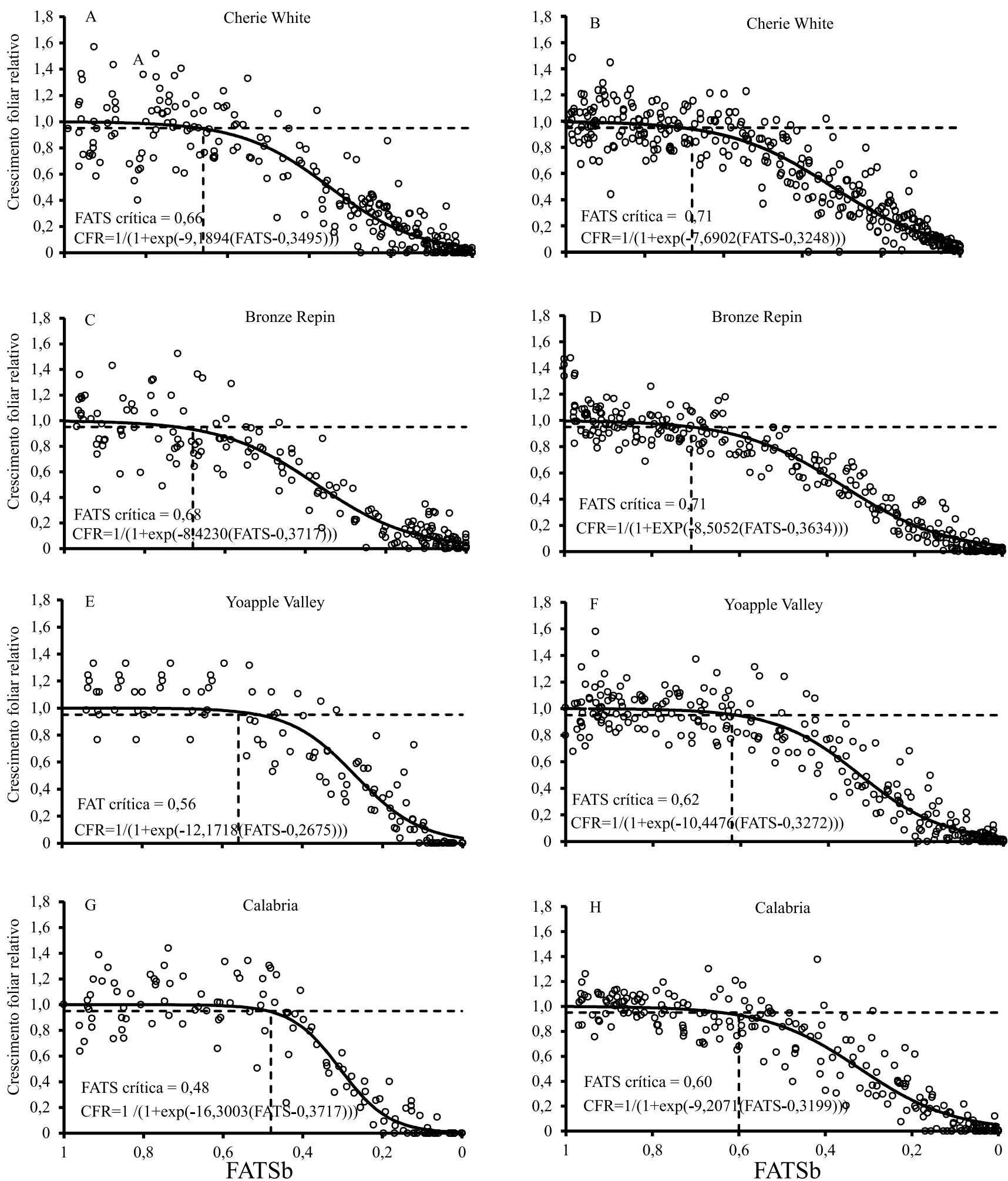

Figura 3. Crescimento foliar relativo (CFR), em função da fração de água transpirável no substrato (FATSb), para as cultivares de crisântemo Cherie White, Bronze Repin, Yoapple Valley e Calabria, cultivadas em casa de vegetação, em dois experimentos, com início da aplicação do deficit hídrico em: 9/12/2011, Época1 (A, C, E e G); e 7/7/2012, Época2 (B, D, F e H). FATSb crítica, fração de água transpirável no substrato, quando se inicia a redução do crescimento foliar relativo das plantas. 
ocorreu mais rapidamente, o que pode ser um indicador de pouca tolerância à deficiência hídrica.

$\mathrm{Na}$ literatura, relata-se a hipótese de que sob baixa demanda evaporativa do ar (baixo DPV), que é o caso de Época1 e Época2 (Kiniry et al., 1998), a limitação do fluxo transpiratório (início do fechamento estomático) ocorreria com um valor de FATS crítica menor (Ray et al., 2002; Lago et al., 2011). No entanto, os valores de FATSbc para a TR e CFR (Figuras 2 e 3 ), obtidos no presente estudo, foram superiores aos encontrados em mandioca e batata, em condição de alta demanda evaporativa do ar (Lago et al., 2011, 2012), contrariando a hipótese comentada pelos autores.

A determinação da FATS crítica para as cultivares de crisântemo pode ser um instrumento para auxiliar na determinação do fator $\mathrm{p}$, utilizado por Heinemann et al. (2011), para determinar a fração de água disponível no solo que pode ser retirada da zona radicular, antes de ocorrer a deficiência hídrica. Assumindo-se que o fator $\mathrm{p}$ ocorra quando a transpiração for potencial, isto é, que a FATS esteja no intervalo em que a TR estiver entre 1,00 a 0,95 , tal fator poderia ser utilizado como instrumento no manejo da irrigação no cultivo de crisântemo. Seria possível, assim, obter um manejo com irrigações menos frequentes e com volumes adequados. Além disso, as informações obtidas no presente estudo podem direcionar o melhoramento genético, para obtenção de genótipos de crisântemo com maior tolerância à deficiência hídrica.

\section{Conclusões}

1. A resposta da transpiração e do crescimento foliar à fração de água transpirável no substrato (FATSb) difere entre as cultivares de crisântemo estudadas.

2. A redução da água disponível no substrato provoca redução do crescimento foliar, antes de restringir a transpiração.

3. As cultivares Cherie White e Bronze Repin são mais tolerantes ao deficit hídrico, por fecharem os estômatos antes e por conservar mais a água no substrato do que as cultivares Yoapple Valley e Calabria.

\section{Agradecimentos}

À Coordenação de Aperfeiçoamento de Pessoal de Nível Superior (Capes, projeto Dinter 2042/2009), pelo apoio financeiro.

\section{Referências}

BINDI, M.; BELLESI, S.; ORLANDINI, S.; FIBBI, L.; MORIONDO, M.; SINCLAIR, T.R. Influence of water deficit stress on leaf area development and transpiration of Sangiovese grapevines grown in pots. American Journal of Enology and Viticulture, v.56, p.68-72, 2005.

BRAY, E.A. Plant responses to water deficit. Trends in Plant Science, v.2, p.48-54, 1997. DOI: 10.1016/S1360-1385(97)82562-9.

BURIOL, G.A.; STRECK, N.A.; PETRY, C.; SCHNEIDER, F.M. Transmissividade a radiação solar do polietileno de baixa densidade utilizado em estufas. Ciência Rural, v.25, p.1-4, 1995. DOI: 10.1590/S0103-84781995000100001.

DAVATGAR, N.; NEISHABOURI, M.R.; SEPASKHAH, A.R.; SOLTANI, A, Physiological and morphological responses of rice (Oryza sativa L.) to varying water stress management strategies. International Journal of Plant Production, v.3, p.19-32, 2009.

FARIAS, M.F. de; SAAD, J.C.C.; VILLAS BÔAS, R.L.; DANTAS, J.S. Manejo da rega na cultura do crisântemo de corte cultivado em ambiente protegido. Revista de Ciências Agrárias, v.35, p.128-133, 2012.

HEINEMANN, A.B.; STONE, L.F.; FAGERIA, N.K. Transpiration rate response to water deficit during vegetative and reproductive phases of upland rice cultivars. Scientia Agricola, v.68, p.24-30, 2011. DOI: 10.1590/S0103-90162011000100004.

KINIRY, J.R.; LANDIVAR, J.A.; WITT, M.; GERIK, T.J.; CAVERO, J.; WADE, L.J. Radiation-use efficiency response to vapor pressure deficit for maize and sorghum. Field Crops Research, v.56, p.265-270, 1998. DOI: 10.1016/S0378-4290(97)00092-0.

LAGO, I.; STRECK, N.A.; BISOGNIN, D.A.; SOUZA, A.T. de; SILVA, M.R. da. Transpiração e crescimento foliar de plantas de mandioca em resposta ao deficit hídrico no solo. Pesquisa Agropecuária Brasileira, v.46, p.1415-1423, 2011. DOI: 10.1590/ S0100-204X2011001100001.

LAGO, I.; STRECK, N.A.; ZANON, A.J.; HANAUER, J.G.; BISOGNIN, D.A.; SILVA, M.R. da. Transpiração e crescimento foliar de clones de batata em resposta à fração de água transpirável no solo. Revista Brasileira de Ciência do Solo, v.36, p.745-754, 2012. DOI: $10.1590 / \mathrm{S} 0100-06832012000300006$.

LECOEUR, J.; SINCLAIR, R.T. Field pea transpiration and leaf growth in response to soil water deficits. Crop Science, v.36, p.331-335, 1996. DOI: 10.2135/cropsci1996.0011183X00360002 0020x.

MARTINS, F.B.; STRECK, N.A.; SILVA, J.C. da; MORAIS, W.W.; SUSIN, F.; NAVROSKI, M.C.; VIVIAN, M.A. Deficiência hídrica no solo e seu efeito sobre transpiração, crescimento e desenvolvimento de mudas de duas espécies de eucalipto. Revista Brasileira de Ciência do Solo, v.32, p.1297-1306, 2008. DOI: 10.1590/S0100-06832008000300037.

MORENO F., L.P. Respuesta de las plantas al estrés por déficit hídrico. Una revisión. Agronomía Colombiana, v.27, p.179-191, 2009.

PINHEIRO, D.G. Plantas de mandioca submetidas a um e dois ciclos de secamento do solo. 2013. 65p. Dissertação (Mestrado) Universidade Federal de Santa Maria, Santa Maria. 
RAY, J.D.; GESCH, R.W.; SINCLAIR, T.R.; ALLEN, L.H. The effect of vapor pressure deficit on maize transpiration response to a drying soil. Plant and Soil, v.239, p.113-121, 2002. DOI: 10.1023/A:1014947422468.

REGO, J. de L.; VIANA, T.V. de A.; AZEVEDO; B.M. de; ARAÚJO, W.F.; FURLAN, R.A.; BASTOS, F.G.C. Produtividade de crisântemo em função de níveis de irrigação. Horticultura Brasileira, v.27, p.45-48, 2009. DOI: 10.1590/ S0102-05362009000100009.

RODRIGUES, M.A. Crescimento e marcha de absorção de nutrientes de crisântemo (Dendranthema grandiflora Tzvelev.) cultivado em vaso. 2013. 191p. Tese (Doutorado) - Escola Superior de Agricultura Luiz de Queiroz, Piracicaba.

SANTOS, R.F.; CARLESSO, R. Déficit hídrico e os processos morfológico e fisiológico das plantas. Revista Brasileira de Engenharia Agrícola e Ambiental, v.2, p.287-294, 1998.
SINCLAIR, T.R.; LUDLOW, M.M. Influence of soil water supply on the plant water balance of four tropical grain legumes. Australian Journal of Plant Physiology, v.13, p.329-341, 1986. DOI: $10.1071 /$ PP9860329.

SOUZA, A.T. de; STRECK, N.A.; HELDWEIN, A.B.; BISOGNIN, D.A.; WINCK, J.E.M.; ROCHA, T.S.M. da; ZANON, A.J. Transpiration and leaf growth of potato clones in response to soil water deficit. Scientia Agricola, v.71, p.96-104, 2014. DOI: 10.1590/S0103-90162014000200002.

STRECK, N.A. Do we know how plants sense a drying soil? Ciência Rural, v.34, p.581-584, 2004. DOI: 10.1590/ S0103-84782004000200039.

TAIZ, L.; ZEIGER, E. Fisiologia vegetal. 4.ed. Porto Alegre: Artmed, 2009. 848p.

WAHBI, A.; SINCLAIR, T.R. Transpiration response of Arabidopsis, maize, and soybean to drying of artificial and mineral soil. Environmental and Experimental Botany, v.59, p.188-192, 2007. DOI: 10.1016/j.envexpbot.2005.12.004.

Recebido em 30 de maio de 2014 e aprovado em 24 de junho de 2015 